\title{
ADMET Polymerization: Greener Method for Synthesis of End-Functionalized Poly(Arylene Vinylene)s
}

\author{
Tahmina Haque1, Kotohiro Nomura ${ }^{2 *}$ \\ ${ }^{1}$ Department of Chemistry, Jahangirnagar University, Dhaka, Bangladesh \\ ${ }^{2}$ Department of Chemistry, Tokyo Metropolitan University, Tokyo, Japan \\ Email: *ktnomura@tmu.ac.jp
}

How to cite this paper: Haque, T. and Nomura, K. (2017) ADMET Polymerization: Greener Method for Synthesis of EndFunctionalized Poly(Arylene Vinylene)s. Green and Sustainable Chemistry, 7, 1-19. https://doi.org/10.4236/gsc.2017.71001

Received: December 29, 2016

Accepted: January 23, 2017

Published: January 26, 2017

Copyright $\odot 2017$ by authors and Scientific Research Publishing Inc. This work is licensed under the Creative Commons Attribution-NonCommercial International License (CC BY-NC 4.0).

http://creativecommons.org/licenses/by-nc/4.0/ (c) (i) (8) Open Access

\begin{abstract}
Recent results for synthesis of conjugated polymers, poly(arylene vinylene)s exemplified as poly(fluorene vinylene)s and poly(phenylene vinylene)s, by acyclic diene metathesis (ADMET) polymerization have been introduced. The methods using molybdenum and ruthenium catalysts afforded defect-free, high molecular weight polymers with all trans olefinic double bonds, and significant reduction of by-products (halogen, sulfur etc.) in addition of decrease of structurally defects have been attained. The methods also demonstrated precise synthesis of end-functionalized polymers that showed unique optical properties combined with the end groups. Catalytic one-pot syntheses of end-functionalized poly(9,9-dialkylfluorene-2,7-vinylene)s have been attained by both ruthenium (by chain-transfer) and molybdenum catalysts and the method should provide more green route for synthesis of conjugated materials with better device performance.
\end{abstract}

\section{Keywords}

Conjugated Polymers, Olefin Metathesis, Precision Polymerization, Defect-Free, End-Functionalization

\section{Introduction: Background}

Conjugated polymers are promising semiconducting electronic materials for numerous applications in optoelectronic and electrochemical devices [1] [2] [3] [4]. It has been considered that synthesis of structurally regular, chemically pure polymers is of critical importance in terms of their application as high-performance polymer electronic devices. Moreover, the end-group modification has also been considered as a promising approach for unique optical and/or elec- 
tronic properties (via energy transfer etc.). Importance of development of new synthetic methods/methodologies has thus been recognized.

Conventional synthesis of poly( $p$-arylene vinylene)s (PPVs) by condensation polymerization in the presence of tetrahydrothiophene generally requires harsh conditions such as high temperature $\left(180^{\circ} \mathrm{C}-300^{\circ} \mathrm{C}\right)$ under vacuum conditions (Scheme 1) [5] [6]. However, a significant decrease in the quantum efficiency of the final PPV film was observed due to formation (by-production) of oxidation products during the conversion step [5] [6]. Moreover, contamination of impurities (halogen, sulfur etc.) affects severe damages toward the device performance.

The other methods such as the Gilch polymerization, Suzuki-Heck or Heck coupling, and Horner-Wittig-Emmons (HWE) reactions [7]-[13] have also been employed as the conventional methods. Gilch polymerization provides some advantages for placement of vinylene units along the polymer backbone with high molecular weights and low PDI $\left(M_{\mathrm{w}} / M_{\mathrm{n}}\right)$ index. In synthesis of poly $(9,9-$ di- $n$-octylfluorene-2,7-vinylene) (PFV) and its copolymers with MEH-PPV (Scheme 2) [7] [8], the key factor for obtainment of high molecular weight polymers was an introduction of a chloromethyl group into the 9,9-di-n-octylfluorene unit [7]. However, significant defect structure was detected in the PFV (and the copolymer) main chain; degree of the defect structure was roughly estimated to be $10 \%$ - 15\% [7]. Hyperbranched PFVs, linear PFV were also prepared from 2,4,7-tris(bromomethyl)-9,9-dihexylfluorene, and 2,7-bis(bromomethyl)-9,9-dihexylfluorene monomers by the Gilch reaction (Scheme 2) [9].

A tandem by using Suzuki-Heck reaction for the polymerization of aryldibromides with $\mathrm{K}^{+}\left[\mathrm{B}\left(\mathrm{CH}=\mathrm{CH}_{2}\right) \mathrm{F}_{3}\right]$ was employed for synthesis of a series of PFVs (Scheme 3(a)) [10]. The method afforded polymers with low percentages of structural 1,1-diarylenevinylene defects. A series of PFV copolymers incorporating bis(phenyl)oxadiazole (OXD), triphenylamine (TPA), or both moieties along the backbone were also synthesized by Heck coupling (Scheme 3(b)) [11]. These, especially Heck type coupling, are method widely employed for synthesis of poly(arylene vinylene)s exemplified in PPVs (Scheme 3(c)) [12]. The resultant PFVs (and PPVs) prepared by these methods shown in Scheme 4 possessed rather low percentage of structural defects compared to those prepared by the Gilch method, however, the polymers possessed a mixture of cis- and trans-olefinic double bonds and control of molecular weight as well as removal of Pd (and exclusion of a possibility of cross linking even small percentage), which would affect the property (quantum efficiency), seemed difficult.

Horner-Emmons method offers a simple strategy for preparing PFVs (Scheme 4(a)) [13]. The resultant PFVs by modified Horner-Emmons route

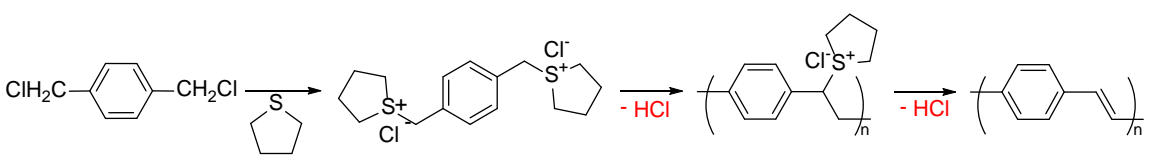

Scheme 1. Synthesis of poly ( $p$-arylene vinylene) by conventional approach (condensation at high temperature in vacuo). 
(a) Synthesis of homopolymer

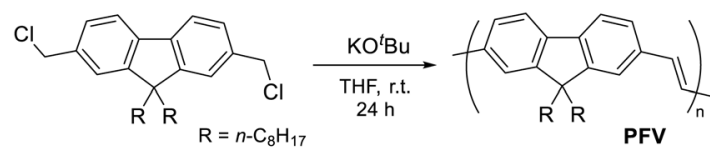

(b) Synthesis of copolymer

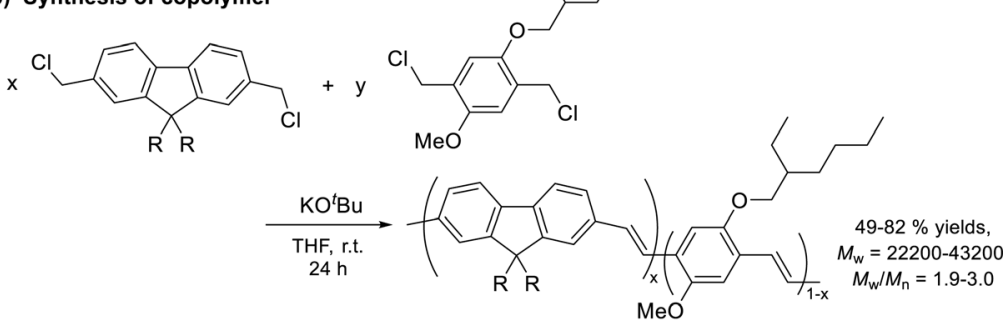

(c) Synthesis of hyperbranched polymer

$x=0.50,0.80,0.90,0.95$

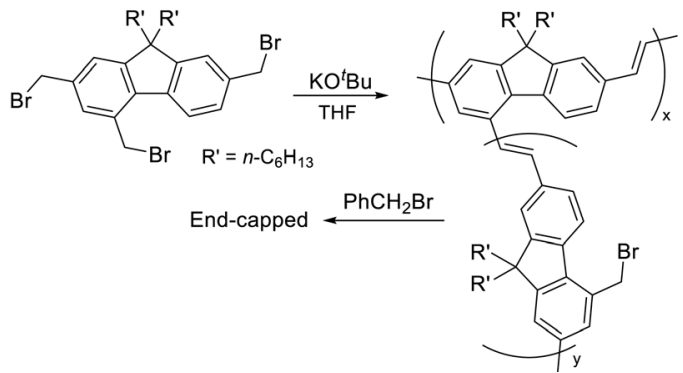

Scheme 2. Syntheses of poly(9,9-di-n-octyl-fluorene-2,7-vinylene) (PFV) and the copolymer by Gilch polymerization [7] [8] [9].

(a) Synthesis of PFVs by Suzuki-Heck Reaction

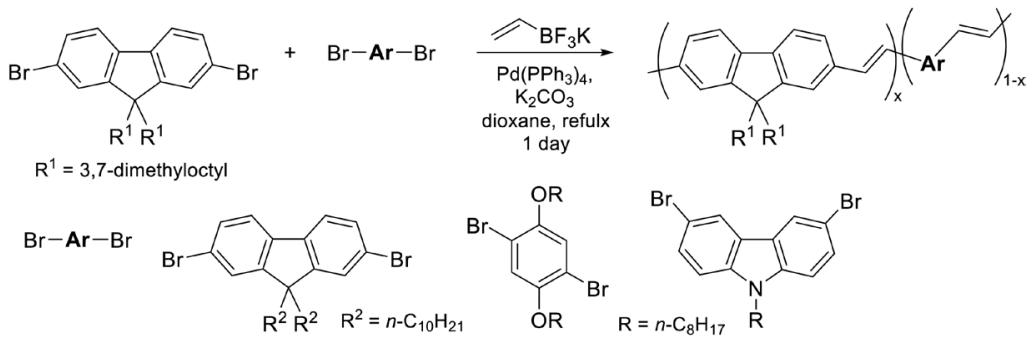

(b) Synthesis of PFVs by Heck Coupling Reaction

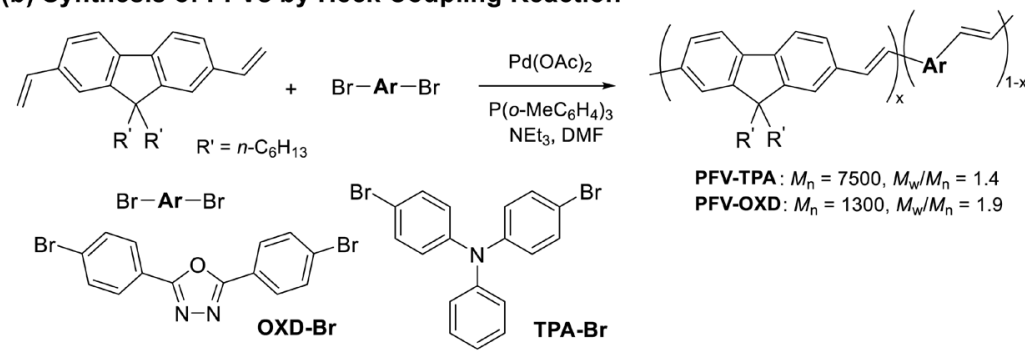

(c) Synthesis of PPVs by Heck Coupling Reaction

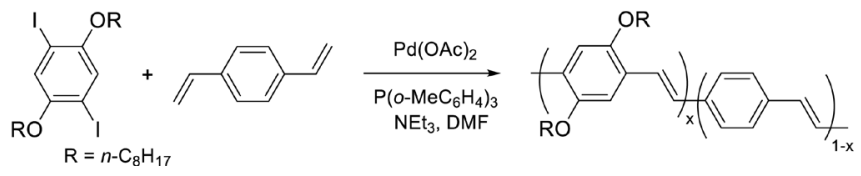

Scheme 3. Synthesis of PFVs by Suzuki-Heck or Heck coupling reactions [10] [11] [12]. 
(a) Synthesis of PFV by Horner-Emmons route

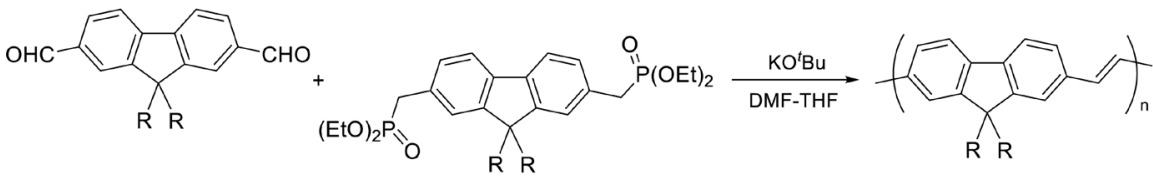

(b) Synthesis of oligo(FV) by step-wise approach

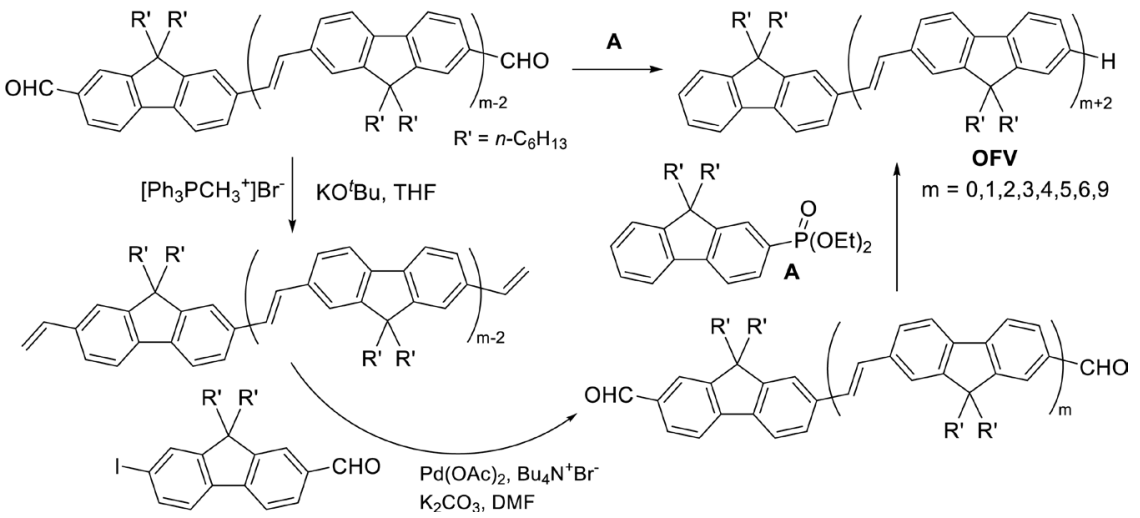

Scheme 4. Horner-Emmons route to synthesis of conjugated polymer [14].

possessed rather lower molecular weights compared to those prepared by established Gilch polymerization route, but relatively higher yields and fewer defects [13]. Interestingly, the PFVs prepared by this route possessed no termination of the conjugation and cross-linking (compared to Gilch and Heck routes), and the resultant polymers thus possessed less structural defect that showed better properties compared to those especially by the Gilch method [13].

Syntheses of a series of oligo(9,9-di-n-octylfluorene-2,7-vinylene)s (OFVs) with strictly conjugation units up to 11 were made according to a divergent approach (Scheme 4(b)) [14]. The OFVs could be prepared by chain growth process, and were well-conjugated system which possessed an effective conjugation length with $19 \mathrm{FV}$ units. Absorption and photoluminescence spectra were red-shifted upon increasing the FV repeat units [14].

In summary (Scheme 5), as described above, there are several concerns for synthesis of conjugated polymers by the conventional methods such as Gilch, HWE, and Heck reaction approaches. Some reactions (ex. the condensation polymerization in the presence of tetrahydrothiophene) require harsh conditions, and contamination of impurities (inorganic salts, sulfur, halogen, Pd metal etc.) affects damages of the device performances significantly; these methods generally require strict purification steps for obtainment of better performance (quantum yields, emission etc.). Difficulty of structural control (cis/trans) in addition to end groups also affects the property of the resultant polymers in terms of application. Therefore, more efficient method for synthesis of structurally regular, chemically pure polymers has thus been desired.

Acyclic diene metathesis (ADMET) polymerization [15] [16] [17] [18] [19] has been recognized as an efficient route for the synthesis of $\pi$-conjugated materials [20]-[35] (Scheme 6). The ADMET polymerization does not require harsh conditions and promote adverse side reactions which might alter the photophysical 
Summary: Conventional Synthetic Route for Synthesis of Poly(arylene vinylene)s

1) Condensation under high temperature in vacuo

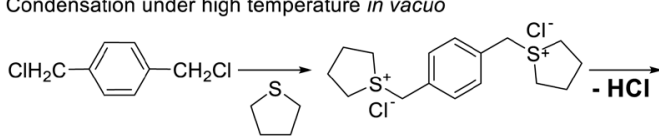

2) Condensation in the presence of inorganic salt (Gilch route)

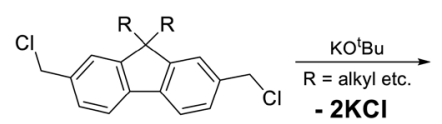

$-2 \mathrm{KCl}$

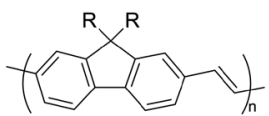

3) Condensation by Horner-Wittig-Emmons (HWE) Reaction

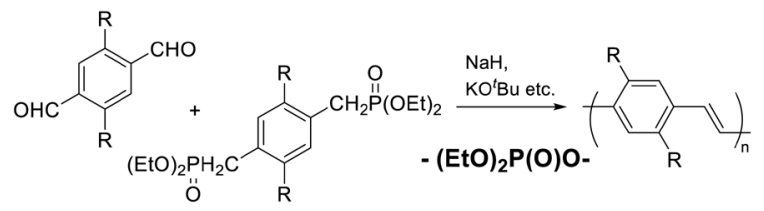

4) Condensation by Heck Reaction<smiles>[R]c1cc(Br)c([R])cc1Br</smiles><smiles>[R]c1cc(C=C)c([R])cc1C=C</smiles><smiles>CCCCC(Br)CBr</smiles><smiles>[R]c1cc(CC)c([R])cc1/C=C/C</smiles>

Diificult to reach completion Termination of conjugation, Required removal of halogen, sulfur

\section{Major Concerns: Defect} 1) By-Production of Halogen (Inorganic halide) $\underline{2}$ equiv./monomer Contamination of impurities Strict purification required 2) Difficult to control MW (chain end?) 3) Regularity (cis/trans)

4) Crosslinking (Heck Coupling)

$\downarrow$

Scheme 5. Summary of conventional methods for synthesis of conjugated polymers.

Acyclic Diene Metathesis (ADMET) Polymerization Route

$\mathrm{n}$

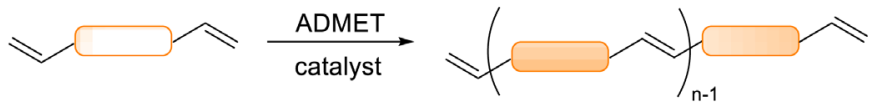<smiles>[R]c1cc(C=C)c([R])cc1C=C</smiles>
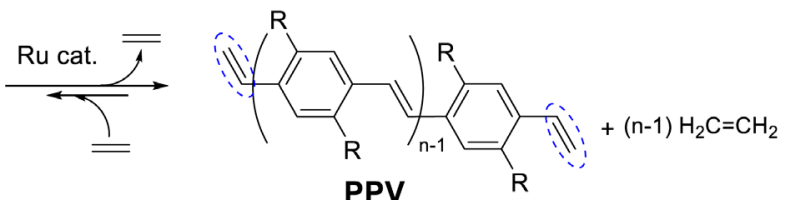<smiles>[R]C1([R])c2cc(C=C)ccc2-c2ccc(C=C)cc21</smiles>

$\mathrm{R}=n$-octyl, 2'-ethylhexyl, $n$-hexyl
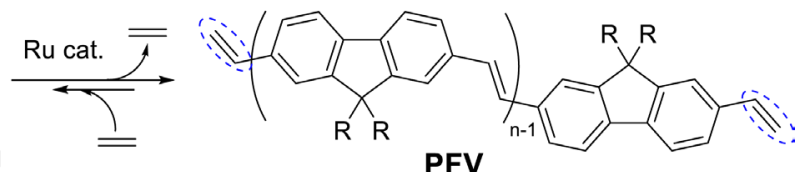

PFV

$+(n-1) \mathrm{H}_{2} \mathrm{C}=\mathrm{CH}_{2}$

$\mathrm{n}$<smiles>[R]n1c2cc(C=C)ccc2c2ccc(C=C)cc21</smiles>

$\mathrm{R}=$ n-octyl, 9'-heptadecanyl
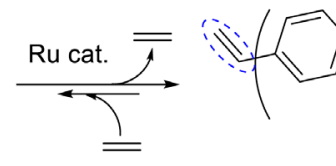

Ru cat.

Attractive Characterisitics

(1) Defect free (no termination of conjugation)

(2) High stereo-regularity (all trans olefinic double bond)

(3) Well-defined polymer chain ends

Scheme 6. Synthesis of conjugated polymers by ADMET polymerization [30] [31] [32] [33].

or other desired properties of the target polymer. This methodology therefore afforded synthesis of defect free, high molecular weight, all trans poly(9,9-di- $n$ - 
octyl-fluorene-2,7-vinylene) (PFV) [30], poly(2,5-dialkyl-pheny-lene-1,4vinylene)s (PPVs) [31], and poly( $N$-alkylcarbazole-2,7-vinylene)s (PCVs) [32], poly(thienylene vinylene)s [34]-[40] by using Schrock type molybdenum-alkylidene, and ruthenium-carbene catalysts (Scheme 6). The resultant polymers [30] [31] [32] possess high stereo-regularity (all trans olefinic double bond) and analytically pure (defect-free), and showed unique photophysical properties compared with polymers prepared by other methods. Moreover, ADMET polymerization offer a unique pathway for the synthesis of specific polymer architectures which might not be attained by other method, as described below.

In this mini review, general characteristics in precise syntheses of poly(arylene vinylene)s by adopting the ADMET polymerization, and further modification of polymers by utilization of this method have been summarized. Moreover, recent progresses on catalytic one-pot synthesis with well-defined end groups have also been reported.

\section{Synthesis of Poly( $p$-Arylene Vinylene) by ADMET Polymerization}

ADMET polymerization of divinyl aromatics (divinylbenzene etc.) is a condensation polymerization that proceeds accompanied by production of ethylene, and the basic reaction mechanism is depicted in Scheme 7. There is an equilibrium in this catalysis and olefinic double bonds in the resultant polymers/oligomers possess highly trans due to steric bulk of the metallacycle intermediate. Although the initial approaches in the ADMET polymerization (of substituted divinylbenezenes) afforded oligomer mixtures [21]-[26], we demonstrated in 2001 for synthesis of high molecular weight poly(9,9-di- $n$-octyl-fluoren2,7-vinylene) by this approach in the presence of molybdenum catalyst, $\mathrm{Mo}\left(\mathrm{CHCMe}_{2} \mathrm{Ph}\right)\left(\mathrm{N}-2,6-\mathrm{Me}_{2} \mathrm{C}_{6} \mathrm{H}_{3}\right)\left[\mathrm{OCMe}\left(\mathrm{CF}_{3}\right)_{2}\right]_{2}$ (Mo-cat.) [30]. In this polymerization, it is important for obtainment of high molecular weight PFV to conduct the polymerization under high monomer concentration with repetitive

ADMET: Acyclic Diene METathesis Polymerization

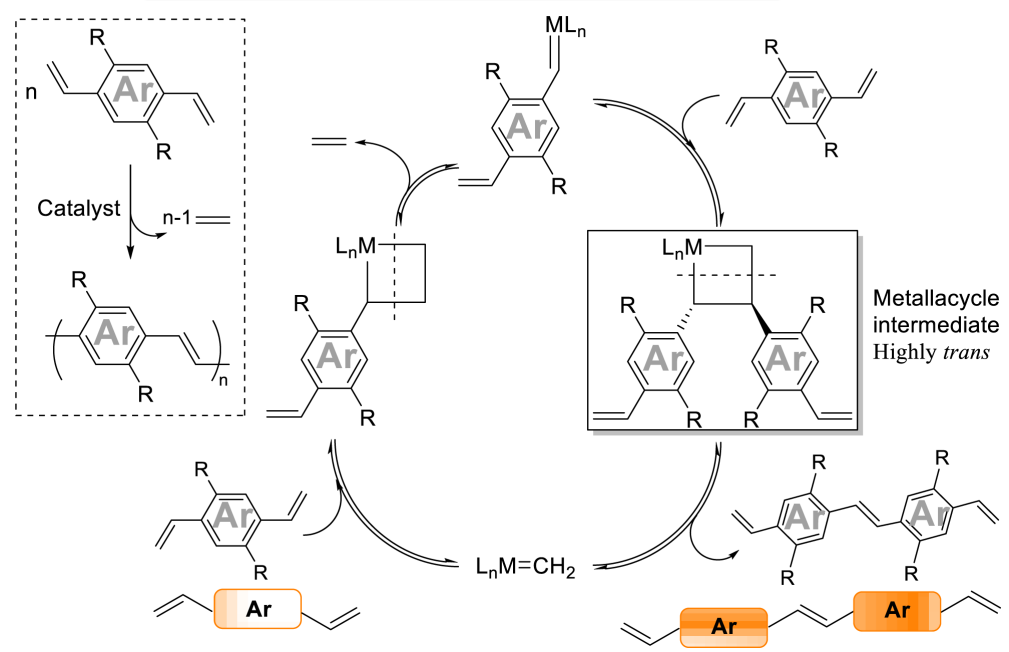

Scheme 7. Basic mechanism on ADMET condensation polymerization. 
removal of ethylene by-produced from the reaction medium. This is basic content that would be considered for the ADMET polymerization, because the ADMET polymerization is an intermolecular metathesis reactions of monomers containing two vinyl (or propenyl) groups as well as condensation polymerization with certain equilibrium. Use of the methyl analogue (Mo-cat.) is also important and the isopropyl analogue, $\mathrm{Mo}\left(\mathrm{CHCMe}{ }_{2} \mathrm{Ph}\right)\left(\mathrm{N}-2,6-{ }^{i} \mathrm{Pr}_{2} \mathrm{C}_{6} \mathrm{H}_{3}\right)\left[\mathrm{OCMe}\left(\mathrm{CF}_{3}\right)_{2}\right]_{2}$, afforded oligomer mixture. Since this is a condensation polymerization accompanied by production of small molecule (ethylene), the molecular weight distribution $\left(M_{\mathrm{w}} / M_{\mathrm{n}}\right)$ should be close to 2 even with unimodal molecular weight distribution.

Table 1 summarizes selected results for ADMET polymerization of 9,9-dialkyl-2,7-divinylfluorene (DVF) by ruthenium complex catalysts (Scheme 8) [32]. The attempted polymerization by $\mathrm{RuCl}_{2}(\mathrm{CHPh})\left(\mathrm{PCy}_{3}\right)_{2}[\mathrm{Ru}(1)]$ recovered DVF, and use of $\mathrm{RuCl}_{2}(\mathrm{CHPh})\left(\mathrm{IMesH}_{2}\right)\left(3-\mathrm{BrC}_{5} \mathrm{H}_{4} \mathrm{~N}\right)_{2}[\mathrm{Ru}(4)]$ gave oligomer mixtures even if the reaction was performed at $90^{\circ} \mathrm{C}$, although $\mathrm{Ru}(4)$ was effective for synthesis of poly(thienylene vinylene)s [34] [35] [36]. $\mathrm{Ru}(\mathrm{CHPh})(\mathrm{Cl})_{2}\left(\mathrm{IMesH}_{2}\right)\left(\mathrm{PCy}_{3}\right)[\mathrm{Ru}(2)]$

Table 1. ADMET polymerization of 9,9-dialkyl-2,7-divinylfluorene (DVF) by Ru-carbene catalysts $[32] .^{a}$

\begin{tabular}{ccccccccc}
\hline Alkyl in $\mathrm{C}_{9} \mathrm{R}$ & $\mathrm{Ru}$ cat. & Solvent & conc. $^{b}$ & temp. $/{ }^{\circ} \mathrm{C}$ & time $/ \mathrm{h}$ & $M_{\mathrm{n}}^{c} \times 10^{-4}$ & $M_{\mathrm{w}} / M_{\mathrm{n}}^{c}$ & yield $^{d} \%$ \\
\hline n-octyl & $\mathbf{2}$ & Toluene & 90 & 50 & 7.5 & 1.84 & 1.8 & 75 \\
n-octyl & $\mathbf{2}$ & Toluene & 180 & 50 & 8 & 2.75 & 2.0 & 90 \\
n-octyl & $\mathbf{4}$ & $\mathrm{C}_{6} \mathrm{H}_{5} \mathrm{Br}$ & 180 & 90 & 3.5 & 0.33 & 1.8 & 75 \\
2'-ethylhexyl & $\mathbf{2}$ & Toluene & 180 & 50 & 3 & 2.10 & 2.1 & 75 \\
2'-ethylhexyl & $\mathbf{2}$ & Toluene & 270 & 50 & 3 & 3.30 & 2.2 & 82 \\
2'-ethylhexyl & $\mathbf{2}$ & Toluene & 180 & 50 & 8 & 3.00 & 2.6 & 79 \\
n-hexyl & $\mathbf{2}$ & Toluene & 100 & 50 & 3 & 2.30 & 2.5 & 93 \\
n-hexyl & $\mathbf{3}$ & Toluene & 200 & 50 & 5 & 2.10 & 2.1 & 82 \\
n-hexyl & $\mathbf{2}^{e}$ & $\mathrm{CH}_{2} \mathrm{Cl}_{2}$ & 103 & 40 & 8 & 3.20 & 2.0 & $>99$ \\
\hline
\end{tabular}

${ }^{a}$ Conditions: solvent $1.0 \mathrm{~mL}, \mathrm{DFV} / \mathrm{Ru}=40$ (molar ratio), $\mathrm{RuCl}_{2}(\mathrm{CHPh})\left(\mathrm{IMesH}_{2}\right)\left(\mathrm{PCy}_{3}\right)\left[\mathrm{Ru}(2), \mathrm{IMesH}_{2}=\right.$ 1,3-bis(2,4,6-trimethylphenyl)-2-imidazolidinylidene], $\mathrm{RuCl}_{2}\left(\mathrm{CH}-2-\mathrm{O}^{\prime} \mathrm{Pr}-\mathrm{C}_{6} \mathrm{H}_{4}\right)\left(\mathrm{IMesH}_{2}\right)$ [Ru(3)], $\mathrm{RuCl}_{2}$ $(\mathrm{CHPh})\left(\mathrm{IMesH}_{2}\right)\left(3-\mathrm{BrC}_{5} \mathrm{H}_{4} \mathrm{~N}\right)_{2}[\mathrm{Ru}(4)]$. ${ }^{b}$ Initial monomer concentration in $\mu \mathrm{mol} / \mathrm{mL}$. ${ }^{c} \mathrm{GPC}$ data in THF vs polystyrene standards. ${ }^{\circledR}$ Isolated yields. ${ }^{e} \mathrm{DVF} / \mathrm{Ru}=35$ (molar ratio), $\mathrm{CH}_{2} \mathrm{Cl}_{2} 2.0 \mathrm{~mL}$.
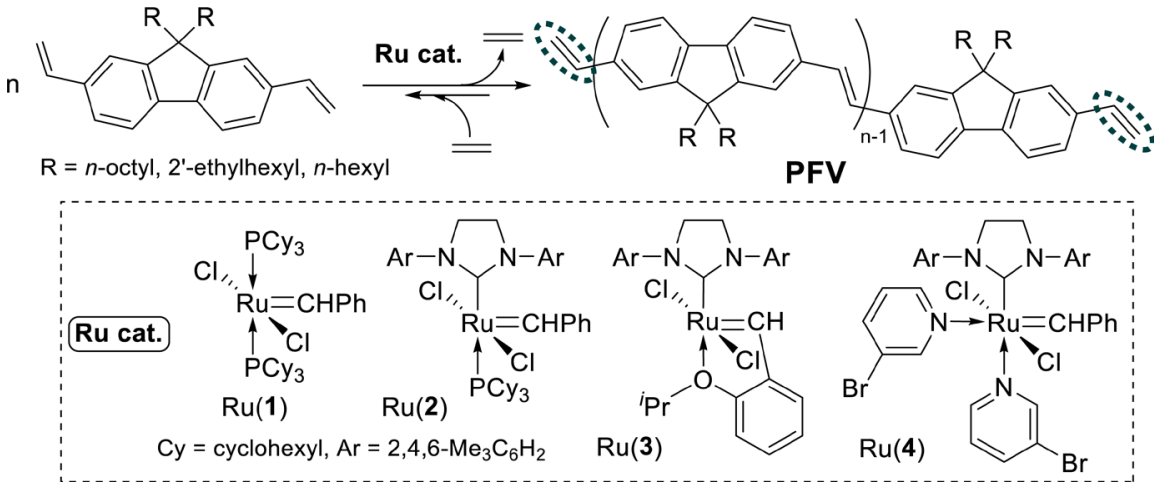

Scheme 8. Synthesis of poly(9,9-dialkyl-fluorene-2,7-vinylene) by ADMET polymerization by $\mathrm{Ru}$-carbene catalysts [32]. 
and $\mathrm{RuCl}_{2}\left(\mathrm{CH}-2-\mathrm{O}^{i} \mathrm{Pr}-\mathrm{C}_{6} \mathrm{H}_{4}\right)\left(\mathrm{IMesH}_{2}\right)[\mathrm{Ru}(3)]$ were effective affording defectfree, all-trans high molecular weight PFVs with unimodal molecular weight distributions [32].

It is noteworthy that olefinic double bonds in the resultant PFVs by the ADMET polymerization using Ru-carbene catalyst possessed exclusive trans regularity ( ${ }^{1} \mathrm{H}$ NMR spectra), and the resultant PFVs possessed vinyl groups at the polymer chain ends [31] [32] [41]; these are notable contrasts with those by the previous (precursor) method [32].

Syntheses of poly(thienylene vinylene)s and their derivatives were reported later by the group of Hillmyer and Wagener (Scheme 9) [34]-[40]. These polymerizations were conducted in 1,2,4-trichlorobenzene at $90^{\circ} \mathrm{C}$ under dynamic vacuum (ca. $100 \mathrm{mTorr}$ ), and up to five aliquots of $1 \mathrm{~mol} \%$ Grubbs' second generation catalyst, $\mathrm{Ru}(2)$, or third generation catalyst, $\mathrm{Ru}(4)$. For obtainment of high molecular weight polymers, solid-statemetathesis polycondensation technique was also employed [35]. Use of propenyl group instead of vinyl group was the key for the success and the resultant polymers were a mixture of cis/trans olefinic double bonds, although reason for the details was not clear.

\section{Introduction of End Functionality into Conjugated Polymers by Olefin Metathesis with Wittig-Type Coupling}

Since, as described above, the resultant PFVs by Ru catalyzed ADMET polymerization possessed vinyl group exclusively [31] [32], modification of the conjugated materials leading to synthesis of well-defined block copolymers can be thus established by exploitation of the chain ends [41]-[46]. An exclusive end-functionalization can be achieved by coupled olefin metathesis of the vinyl chain ends with Mo cat. with subsequent Wittig-type cleavage with aldehyde (Scheme 10) [41]-[49]. We demonstrated that their emission properties (including quantum yields, lifetime etc.) were affected by certain end functionalities. This means that the emission properties can be modified by number of the FV repeat units, end groups (chromophore) and the middle segment: PFV$(\text { F-BODIPY })_{2}$ exhibit white-light emission with high quantum efficiency [44].
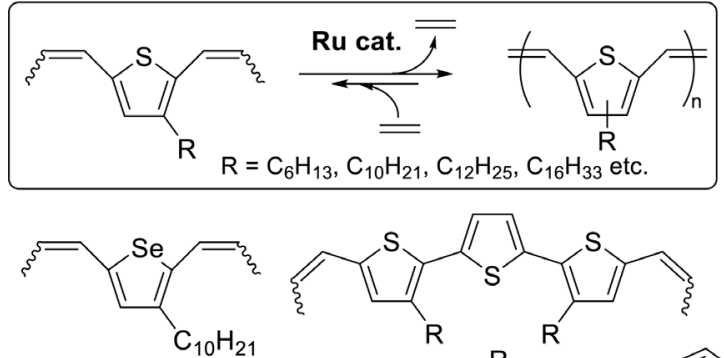<smiles>[Z]C=Cc1cc([R])c(-c2ccc(-c3sc(/C=C\C)cc3[R])s2)s1</smiles><smiles>[R]C=Cc1ccc(-c2ccc(/C=C\C)s2)s1</smiles><smiles>C/C=C\c1cc(OCCCC)c(/C=C\C)s1</smiles>

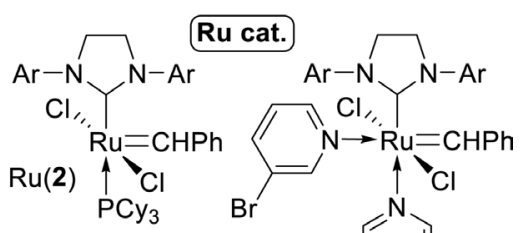
Cy $=$ cyclohexyl,
$\mathrm{Ar}=2,4,6-\mathrm{Me}_{3} \mathrm{C}_{6} \mathrm{H}_{2}$<smiles>Brc1cccnc1</smiles>

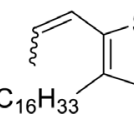

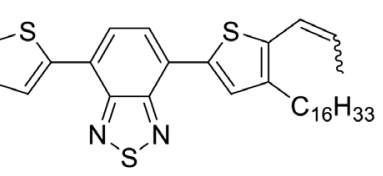

Scheme 9. Synthesis of poly(thienylene vinylene) by ADMET polymerization using Ru-carbene catalysts [34]-[40]. 
One demonstration reported in 2011 was that intensities at ca. 497 - 500, 528 $531 \mathrm{nmin}$ the fluorescence spectra for PFVs containing 3 or 4 thiophene repeat units (PFV-3T, PFV-MP3T, PFV-DH4T) were apparently higher than those in PFV and the others (PFV-2T, PFV-6T) [42]. Moreover, their fluorescence life times $\left(\lambda_{\mathrm{em}}=530-609 \mathrm{~nm}\right.$ in THF $)(\tau=0.654,0.746,0.697 \mathrm{~ns}$, respectively) are longer than those in the others $(0.521,0.534 \mathrm{~ns}$, respectively). The emission intensities were also influenced by the PFV conjugation length (FV repeat unit), and we assumed that the observed differences are thus due to an energy transfer from the PFV conjugated main chain to the oligo(thiophene)moieties (Figure 1).

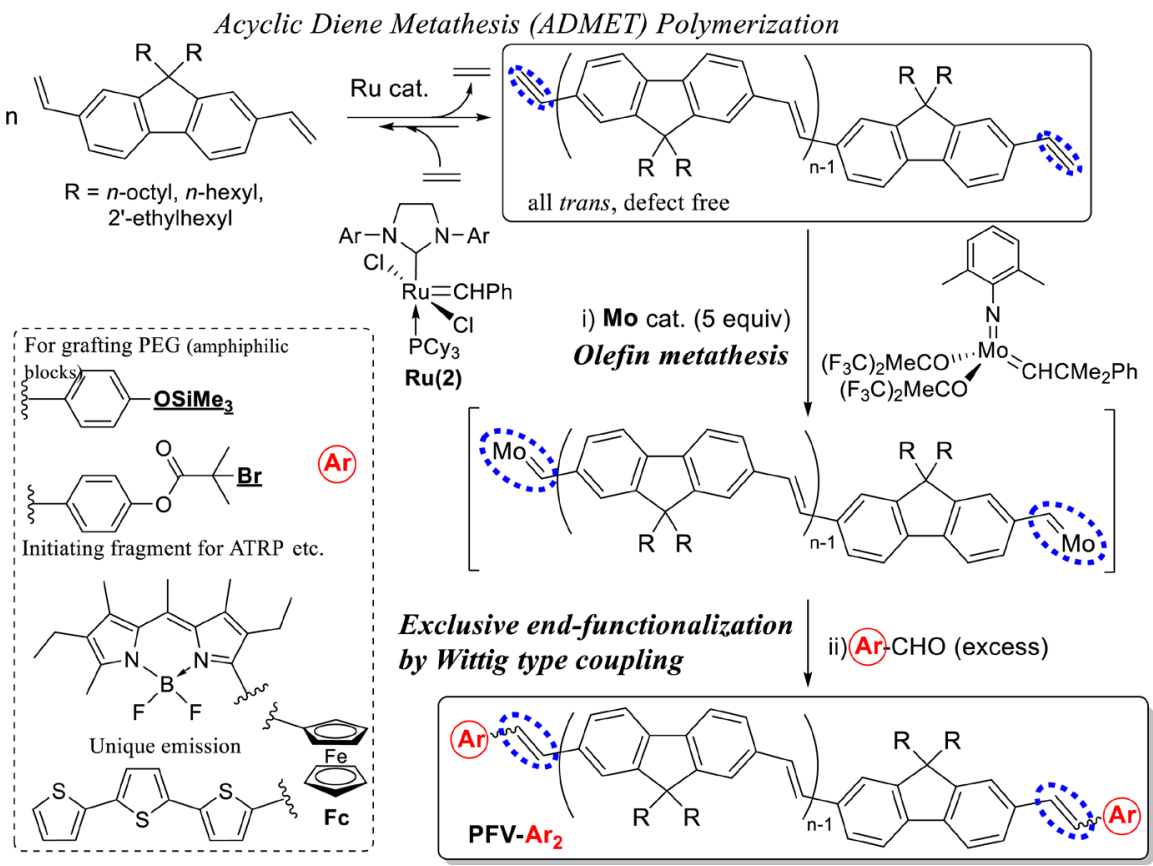

Scheme 10. Synthesis of PFVs with well-defined end groups by combined olefin metathesis with wittig-type coupling [41] [42] [43] [44] [45].

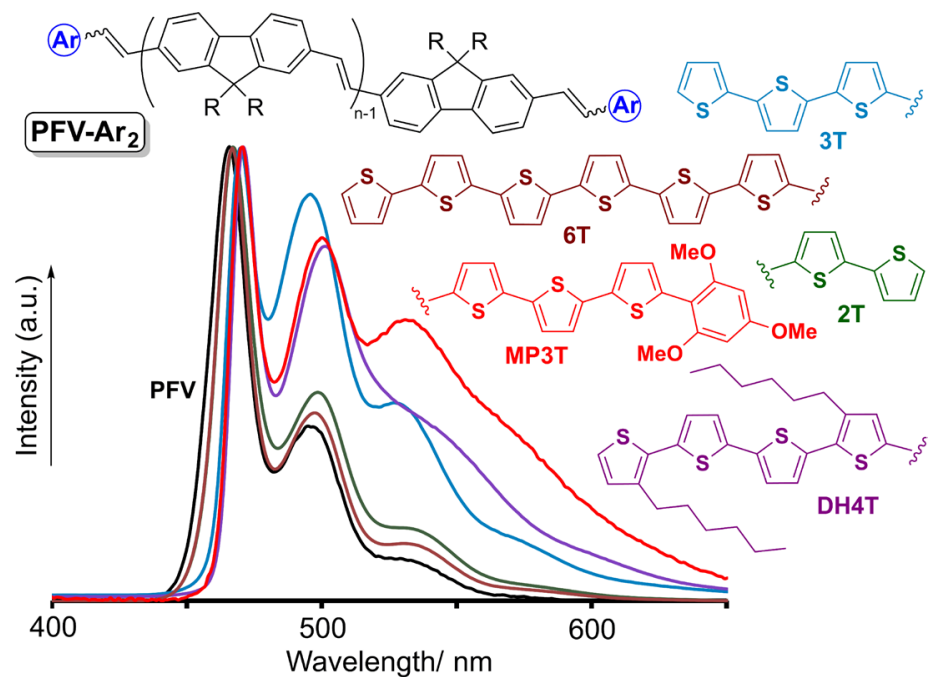

Figure 1. Fluorescence spectra for PFVs containing various oligo(thiophene)s (conc. $1.0 \times 10^{-6} \mathrm{M}$ in THF at $25^{\circ} \mathrm{C}$, excitation at $460 \mathrm{~nm}$ ) [42]. 
Exclusive synthesis of amphiphilic ABA type triblock copolymers could be demonstrated by grafting PEG into both the PFV chain ends (Scheme 11) [41]. For this purpose, phenolic hydroxy group protected by $\mathrm{SiMe}_{3}$ group could be introduced by olefin metathesis of the vinyl groups in the PFV chain ends with Mo cat. and subsequent reaction with $4-\mathrm{Me}_{3} \mathrm{SiOC}_{6} \mathrm{H}_{4} \mathrm{CHO}$. The $\mathrm{SiMe}_{3}$ group at the both polymer chain ends pave the way for the synthesis of desired triblock copolymers, because it can easily be cleaved by treating with $\mathrm{HCl}$ aq. to afford $\mathrm{PFV}-\mathrm{OH}$ which is then treated with $\mathrm{KH}$ in THF followed by the reaction with mesylated poly(ethylene glycol) (PEGMs 2 ) to afford ABA-type amphiphilic triblock copolymers via so called "grafting to" approach. The $M_{\mathrm{n}}$ values in the resultant triblock copolymers estimated by the integration ratios with methylene protons of the PEG segment were highly close to the estimated value from both GPC $\left[M_{\mathrm{n}(\text { calc. })}=M_{\mathrm{n}(\mathrm{GPC})} / 1.6\right]$ and the starting PEG [41]. Synthesis of ABA type
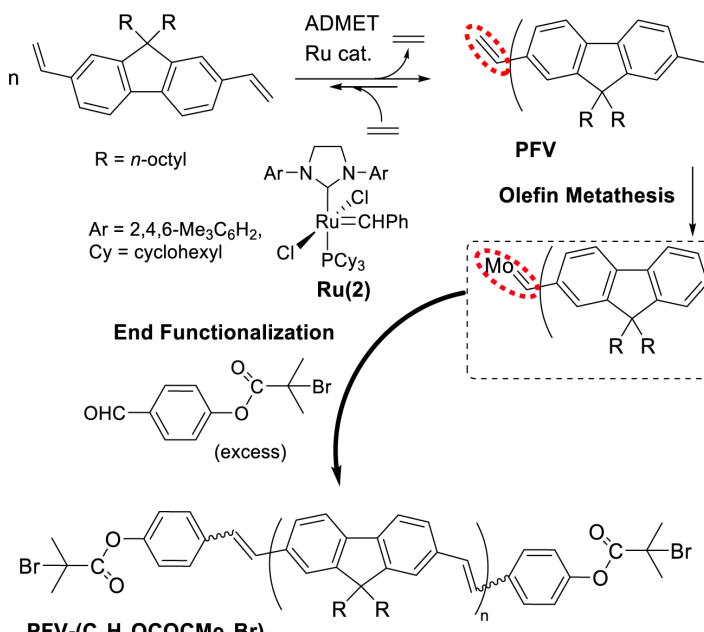

PFV-( $\left.\mathrm{C}_{6} \mathrm{H}_{4} \mathrm{OCOCMe}{ }_{2} \mathrm{Br}\right)_{2}$
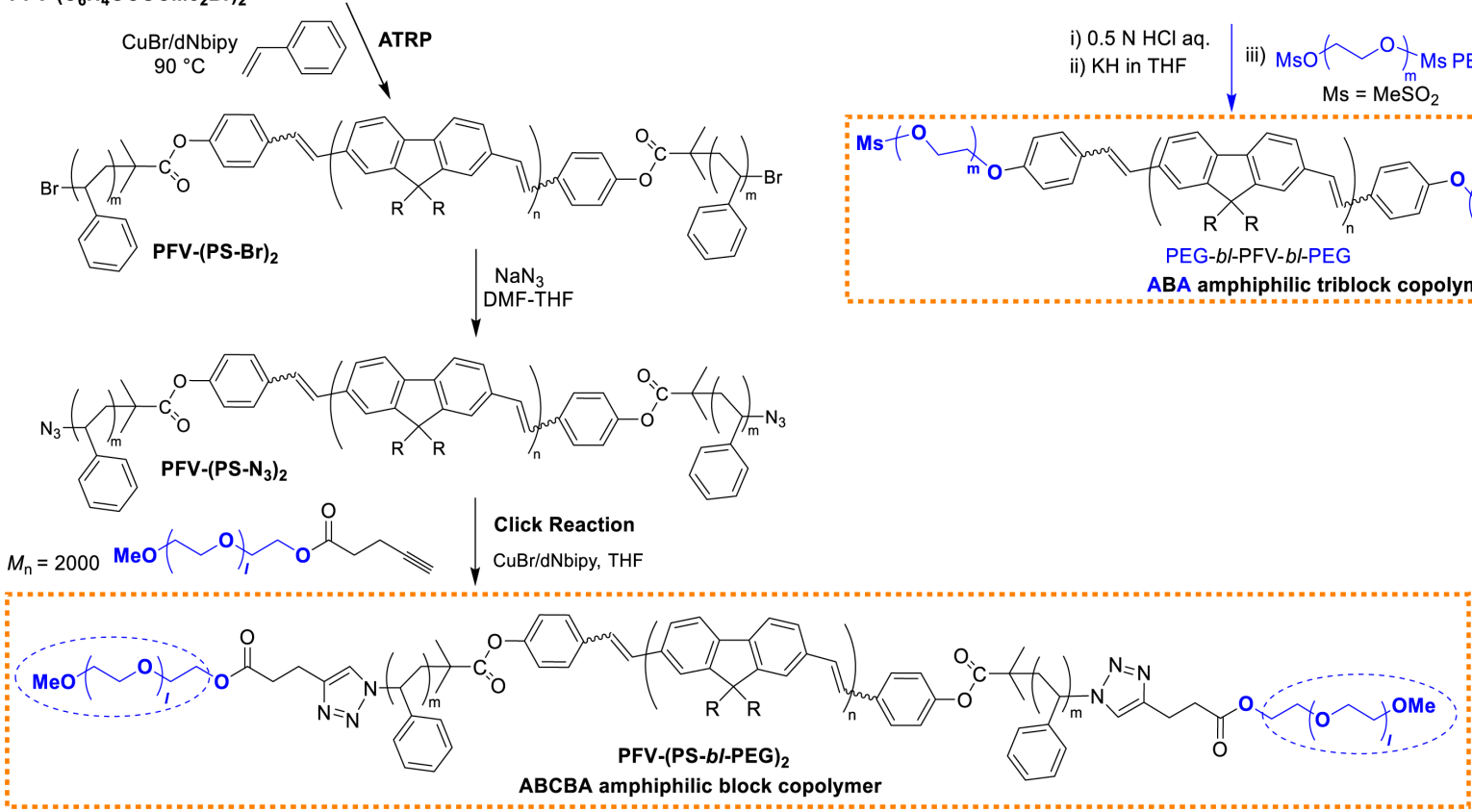

Scheme 11. Synthesis of amphiphilic ABA or ABCBA type multi-block copolymers by combination of ADMET polymerization with other methodologies [41] [43]. 
triblock (graft) copolymers was also demonstrated (via so called "grafting from" approach) by combination of the ADMET polymerization with $\mathrm{Cu}$-catalyzed atom transfer radical polymerization (ATRP). ATRP of styrene in the presence of macroinitiator, PFV $\left(\mathrm{C}_{6} \mathrm{H}_{4} \mathrm{OCOCMe} \mathrm{Br}_{2}\right)_{2}$ (Scheme 11), which could be prepared by an introduction of the initiating functionalities into the PFVs chain ends, was conducted in the presence of $\mathrm{CuBr}$, dNbipy (4,4-dinonyl-2,2-dipyridyl) at $90^{\circ} \mathrm{C}$ [43]. It is noteworthy that the subsequent end-modification by treatment of the $\mathrm{Br}$ at the chain groups with $\mathrm{NaN}_{3}$, and following click reaction with 4-pentanoate terminatedpoly(ethylene glycol)methyl ether (PEG containing acetylene unit) afforded amphiphilic ABCBA-type block copolymers in a precise manner by incorporation of PEG segment confirmed by the ${ }^{1} \mathrm{H}$ NMR spectra (Scheme 11). The $M_{\mathrm{n}}$ values estimated by ${ }^{1} \mathrm{H}$ NMR spectra were highly close to those calculated [43], indicating that each reactions (end-modifications) tool place in a precise, quantitative manner.

Efficient one pot synthesis of end-functionalized triblock copolymers, expressed as $\left[(\mathrm{PFV})_{2}-7 \mathrm{PV}\right] \mathrm{Ar}_{2},\left[(\mathrm{PFV})_{2}-3 \mathrm{PV}\right] \mathrm{Ar}_{2}$ or $\left[(\mathrm{PFV})_{2}-3 \mathrm{~T}\right] \mathrm{Ar}_{2}\left[\mathrm{Ar}=\mathrm{C}_{6} \mathrm{H}_{5}\right.$, $\mathrm{C}_{6} \mathrm{~F}_{5}$, terthiophene $(3 \mathrm{~T})$, ferrocene $\left.(\mathrm{Fc})\right]$,was demonstrated by the following procedure (Scheme 12) [45]: 1) olefin metathesis of the vinyl groups in the PFVs'

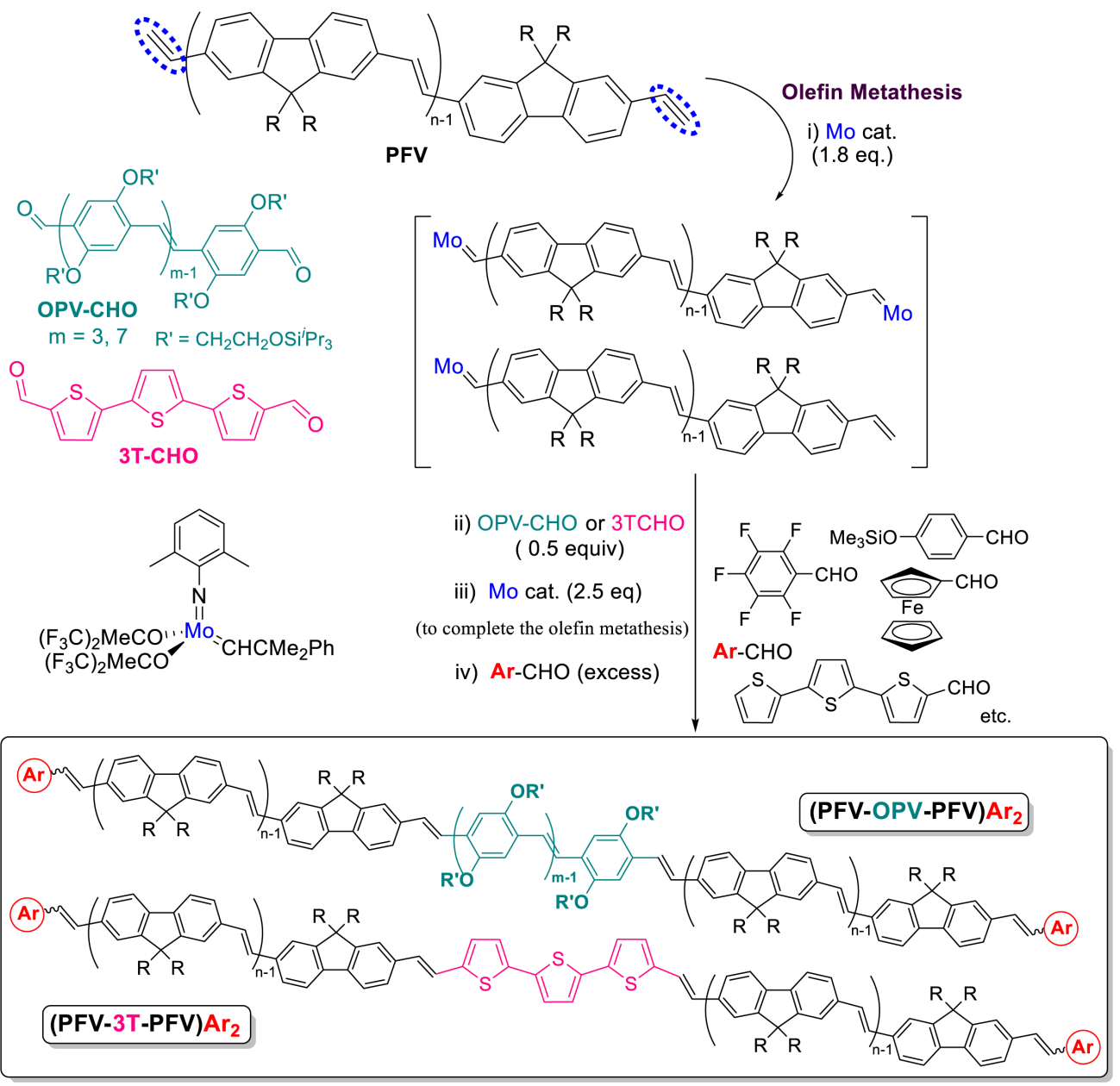

Scheme 12. One pot synthesis of end-functionalized triblock conjugated copolymers [45]. 
chain ends with Mo cat. (1.8 equiv to PFV) afforded a mixture of the "monoand bis-alkylidene" species in situ, 2) Wittig-type coupling with OPVCHO (3PVCHO, $7 \mathrm{PVCHO}$ ) or $3 \mathrm{~T}(\mathrm{CHO})_{2}$ (0.5 equiv), 3) additional olefin metathesis with Mo cat. (2.5 equiv) to complete the olefin metathesis (with the vinyl group in the PFV chain ends), and 4) subsequent addition of aldehyde ( $\mathrm{ArCHO}$ ) in excess amount (70\% - 88\% yields on the basis of PFVs) [45]. The resultant polymers possessed uniform molecular weight distributions $\left(M_{\mathrm{w}} / M_{\mathrm{n}}=1.33-1.63\right)$ without significant increases in their $M_{\mathrm{n}}$ values even after these modification procedures. The ${ }^{1} \mathrm{H}$ NMR spectra clearly indicate disappearance of protons of the vinyl groups in the starting PFVs and presence of resonances ascribed to protons in the middle segment, especially $7 \mathrm{PV}$ or $3 \mathrm{PV}$. Moreover, the $M_{\mathrm{n}}$ values by their integration ratios [on the basis of the middle segments, expressed as $M_{\mathrm{n} \text { (NMR) }}$ ] were highly analogous to the calculated values [expressed as $M_{\mathrm{n}(\text { calcd) }}$ ], strongly suggesting exclusive formations of [(PFV $\left.)_{2}-7 \mathrm{PV}\right] \mathrm{Ar}_{2},\left[(\mathrm{PFV})_{2}-3 \mathrm{PV}\right] \mathrm{Ar}_{2}$, [(PFV $\left.)_{2}-3 \mathrm{~T}\right] \mathrm{Ar}_{2}$ by adopting this methodology [45].

A facile one-pot synthesis of star shape (triarm) polymers containing a PFV main chain with well-defined end groups has also been achieved (Scheme 13)

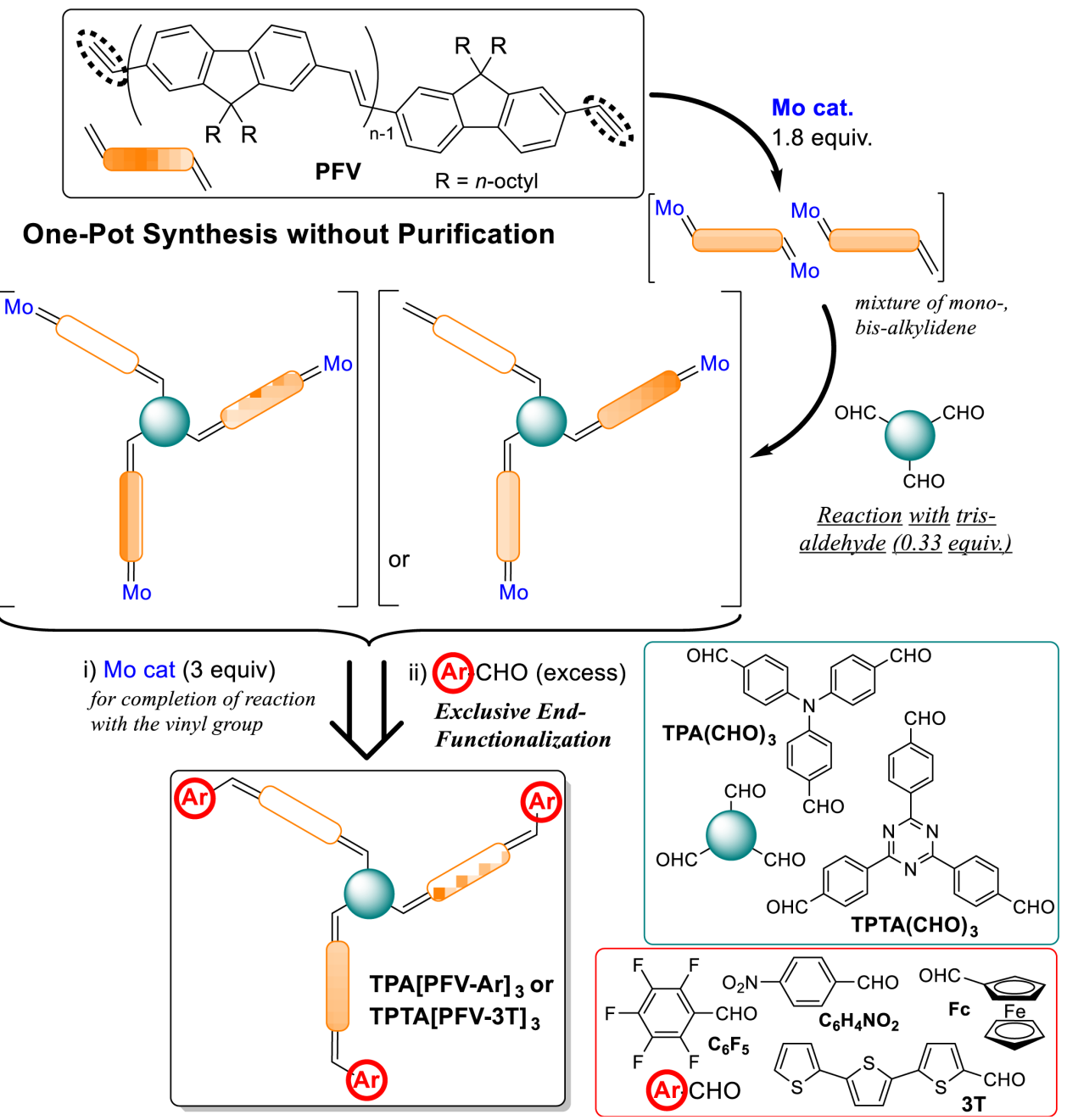

Scheme 13. One pot synthesis of end-functionalized star (tri-arm) (co)polymers [46]. 
adopting the above methodology. Tris(formylphenyl)amine was used as a core, and the triblock copolymers [by incorporation of tri(2,5-dialkoxy-1,4-phenylene vinylene) or terthiophene units as the middle segment in PFVs main chain] were utilized as the arm segments to construct the star polymers [46]. The resultant polymers were identified by ${ }^{1} \mathrm{H}-\mathrm{NMR}$ and GPC traces: the $M_{\mathrm{n}}$ values in the samples were close to the estimated values with unimodal molecular weight distributions $\left(M_{\mathrm{w}} / M_{\mathrm{n}}=1.22-2.00\right)$.

\section{Catalytic One-Pot Synthesis of Poly(9,9-di-n-Octylfluorenevinylene)s by ADMET Polymerization}

Although the above method enables precise and exclusive synthesis of the desired fully end-functionalized conjugated polymers [45] [46] using molybdenum-alkylidene catalyst, the direct chain transfer pathway [50] [51] [52] [53] [54] is another very attractive methodology for "catalytic" synthesis of endfunctionalized conjugated polymers. Therefore, the results explored for the "catalytic one-pot synthesis" by the ADMET polymerization in the presence of chain transfer agent (bifunctional/1,2-disubstituted olefins) using Ru-carbene catalyst [53] have been discussed herein.

Although the above method enables precise and exclusive synthesis of the desired fully end-functionalized conjugated polymers [41]-[46], however, rather excess amount ( $>2$ equiv to vinyl group) of Mo-alkylidene catalyst/reagent (Mo cat.), which has to be prepared through several synthetic steps, is required for completion of the end-functionalization [41]-[46] [48] [49]. Therefore, it is surely desired to develop another methodology for "catalytic" synthesis of endfunctionalized conjugated polymers either from PFVs containing vinyl groups or from DVF directly.

More recently, we have presenteda "catalytic" one-pot synthesis of end-functionalized poly(9,9-di- $n$-octylfluorene-2,7-vinylene)s (EF-PFVs) by acyclic diene metathesis (ADMET)polymerization and olefin metathesis with 1,2-disubstituted olefins (DOs) using Ru catalyst (Scheme 14, Method B) [53]. This method is modified approach employed for synthesis of end-functionalized polymers by ring-opening metathesis polymerization in the presence of ruthenium catalysts [50]. Synthesis of high molecular weight PFVs with efficient end-functionalization have been achieved when DOs were added after the initial ADMET polymerization; 2 step addition [of 1,4-cis-diacetoxy-2-butene (DAB), cis-stilbene (SB), cis-4-octene (OC)] seem suited to the purpose. Although certain optimizations are necessary for the exclusive synthesis of EF-PFVs, significant reduction of amount of molybdenum catalyst/reagent ( $>2$ equiv to the vinyl group) have been attained by adopting this one-pot synthesis approach. Moreover, the resultant PFVs possessed high stereo-regularity (all trans), defect-free nature [53], the results through this study shall pave a new possibility for the precise synthesis of catalytic one-pot synthesis of end-functionalized conjugated polymers.

Moreover, precise, one-pot synthesis of end-functionalized conjugated polymers, 


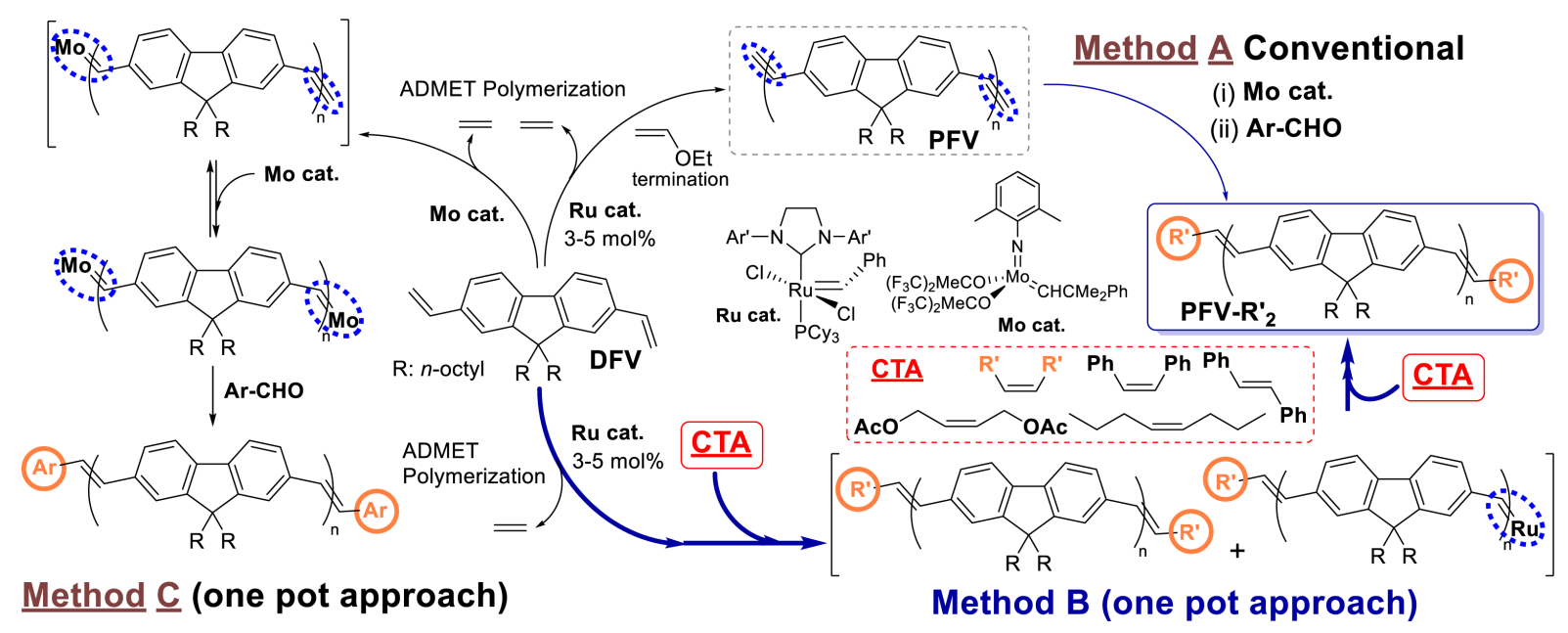

Scheme 14. Precise synthesis of end-functionalized PFVs by acyclic diene metathesis (ADMET) polymerization [53] [54].

poly(9,9-di- $n$-octyl-fluorene vinylene)s (PFVs), have also been achieved (Scheme 14, Method C) by ADMET polymerization followed by Wittig-type coupling with aldehyde in the presence of molybdenum-alkylidene catalyst (Mo cat) [53]. Further addition of Mo cat. after the ADMET polymerization was necessary for completion of olefin metathesis (with the vinyl chain end) and for exclusive end-functionalization by the subsequent coupling. Various end-functionalities could be introduced without purification or isolation by this one-pot methodology.

\section{Summary and Outlook}

Recent results for synthesis of conjugated polymers, poly(arylene vinylene)s exemplified as poly(fluorene vinylene)s and poly(phenylene vinylene)s, by acyclic diene metathesis (ADMET) polymerization approach have been summarized. The methods using molybdenum and ruthenium catalysts afforded defect-free, high molecular weight polymers with all trans olefinic double bonds, and significant reduction of by-products (halogen, sulfur etc.) in addition of decrease of structurally defects (termination of conjugation, a possibility of cross-linking etc.) have been attained. The methods also demonstrated precise synthesis of end-functionalized conjugated polymers by combined olefin metathesis with Wittig-type coupling with various aldehydes. The resultant polymers showed unique optical properties combined with the end groups. Moreover, the method demonstrated synthesis of various end-functionalized block copolymers (by grafting to and grafting from approaches) as well as star shaped (tri-arm) copolymers in one pot with high efficiency. Catalytic one-pot syntheses of end-functionalized poly(9,9-dialkylfluorene-2,7-vinylene)s have been attained by both ruthenium (by chain-transfer) and molybdenum catalysts and the method should provide more green route for synthesis of conjugated materials with better device performance. As described in the introductory, the method demonstrates efficient catalytic synthesis of defect-free (no termination of conjugation, all trans) polymers and does not require strict purification process compared 
with the conventional process (Gilch, HWE, Heck coupling etc.). Moreover, control of molecular weight as well as end-group can be achieved only by adopting this methodology. We highly believe the method would provide a new possibility for development of new materials with unique performances especially by integration of functionality.

\section{Acknowledgements}

The project is partly supported by Advanced Catalytic Transformation for Carbon utilization (ACT-C), Japan Science and Technology Agency (JST). The project at the initial stage was partly supported by Kansai Research Foundation for technology promotion. K.N. expresses his thanks to former/present members who contributed as the coauthors, and his heartfelt thanks to Prof. Dr. Yves Geerts (Laboratoire de Chimie des Polymères, Universitè Libre de Bruxelles) for helpful comments, discussions, and collaboration.

\section{References}

[1] Müllen, K. (2006) Organic Light Emitting Devices. Scherf, U., Ed., Wiley-VCH, Winheim.

[2] Skotheim, T. (2007) Handbook of Conducting Polymers. 3rd Edition, Reynolds, J. Ed., CRC Press, Boca Raton.

[3] Jenekhe, S.A. (2004) Special Issue in Organic Electronics. Chemistry of Materials, 16, 4381-4842. https://doi.org/10.1021/cm041000r

[4] Grimsdale, A.C., Chan, K.L., Martin, R.E., Jokisz, P.G. and Holmes, A.B. (2009) Synthesis of Light-Emitting Conjugated Polymers for Applications in Electroluminescent Devices. Chemical Reviews, 109, 897-1091. https://doi.org/10.1021/cr000013v

[5] Burn, P.L., Bradley, D.D.C., Friend, R.H., Halliday, D.A., Holmes, A.B., Jackson, R.W. and Kraft, A. (1992)Precursor Route Chemistry and Electronic Properties of Poly(p-phenylenevinylene), Poly[(2,5-dimethyl-p-phenylene)vinylene], and Poly[(2,5dimethoxy-p-phenylene)vinylene]. Journal of the Chemical Society, Perkin Transactions, 1, 3225-3231. https://doi.org/10.1039/p19920003225

[6] van Breemen, A.J.J.M., Issaris, A.C., de Kok, M.M., van der Borght, M.J.A.N., Adriaensens, P.J., Gelan, J.M.J.V. and vander Zande, D.J.M. (1999) Optimization of the Polymerization Process of Sulfinyl Precursor Polymers toward Poly(p-phenylenevinylene). Macromolecules, 32, 5728-5735. https://doi.org/10.1021/ma9902246

[7] Jin, S.-H., Park, H.-J., Kim, J.Y., Lee, K., Lee, S.-P., Moon, D.-K., Lee, H.-J. and Gal, Y.-S. (2002) Poly(fluorenevinylene) Derivative by Gilch Polymerization for LightEmitting Diode Applications. Macromolecules, 35, 7532-7534.

https://doi.org/10.1021/ma020671c

[8] Jin, S.-H., Kang, S.-Y., Kim, M.-Y. and Chan, Y.U. (2003) Synthesis and Electroluminescence Properties of Poly(9,9-di-n-octylfluorenyl-2,7-vinylene) Derivatives for Light-Emitting Display. Macromolecules, 36, 3841-3847.

https://doi.org/10.1021/ma0300490

[9] Tsai, L.-R. and Chen, Y. (2008) Hyperbranched Poly(fluorenevinylene)s Obtained from Self-Polymerization of 2,4,7-Tris(bromomethyl)-9,9-dihexylfluorene. Macromolecules, 41, 5098-5106. https://doi.org/10.1021/ma800545z

[10] Grisorio, R., Mastrorilli, P., Nobile, C.F., Romanazzi, G. and Suranna, G.P. (2005) A 
Novel Synthetic Protocol for Poly(fluorenylenevinylene)s: A Cascade Suzuki-Heck Reaction. Tetrahedron Letters, 46, 2555-2558. https://doi.org/10.1016/j.tetlet.2005.02.090

[11] Mikroyannidis, J.A., Gibbons, K.M., Kulkarni, A.P. and Jenekhe, S.A. (2008) Poly(fluorenevinylene) Copolymers Containing Bis(phenyl)oxadiazole and Triphenylamine Moieties: Synthesis, Photophysics, and Redox and Electroluminescent Properties. Macromolecules, 41, 663-674.

[12] Bao, Z., Chen, Y., Cai, R. and Yu, L. (1993) Conjugated Liquid-Crystalline Polymers Soluble and Fusible Poly(phenylenevinylene) by the Heck Coupling Reaction. Macromolecules, 26, 5281-5286. https://doi.org/10.1021/ma00072a002

[13] Anuragudom, P., Newaz, S.S., Phanichphant, S. and Lee, T.R. (2006) Facile Horner-Emmons Synthesis of Defect-Free Poly(9,9-dialkylfluorenyl-2,7-vinylene). Macromolecules, 39, 3494-3499.

[14] Liu, Q., Liu, W., Yao, B., Tian, H., Xie, Z., Geng, Y. and Wang, F. (2007) Synthesis and Chain-Length Dependent Properties of Monodisperse Oligo(9,9-di-n-octylfluorene-2,7-vinylene)s. Macromolecules, 40, 1851-1857.

[15] Lehman, S.E.J. and Wagener, K.B. (2003) ADMET Polymerization. In: Grubbs, R.H., Ed., Handbook of Metathesis, Vol. 3, Wiley-VCH, Weinheim, 283-353.

[16] Baughman, T.W. and Wagener, K.B. (2005) Recent Advances in ADMET Polymerization. In: Buchmeiser, M.R., Ed., Advances in Polymer Science, Vol. 176, Springer, Heidelberg, 1-42.

[17] Berda, E.B. and Wagener, K.B. (2012) Advances in Acyclic Diene Metathesis Polymerization. In: Matyjaszewski, K. and Müllen, M., Eds., Polymer Science: A Comprehensive Reference, Vol. 5, Elsevier BV, Amsterdam, 195-216.

[18] Berda, E.B. and Wagener, K.B. (2012) Recent Advances in ADMET Polycondensation Chemistry. In: Schluter, D., Hawker, C. and Sakamosto, J., Eds., Synthesis of Polymers; New Structures and Methods, Wiley-VCH, Weinhein, 587-600.

[19] Atallah, P., Wagener, K.B. and Schulz, M.D. (2013) ADMET: The Future Revealed. Macromolecules, 46, 4735-4741. https://doi.org/10.1021/ma400067b

[20] Haque, T. and Nomura, K. (2015) Acyclic Diene Metathesis (ADMET) Polymerization for Precise Synthesis of Defect-Free Conjugated Polymers with Well-Defined Chain Ends. Catalysts, 5, 500-517. https://doi.org/10.3390/catal5020500

[21] Thorn-Csányi, E. and Kraxner, P. (1995) Synthesis of Soluble, All-Trans Poly(2,5diheptyl-p-phenylenevinylene) via Metathesis Polycondensation. Macromolecular Rapid Communications, 16, 147-153.

[22] Thorn-Csányi, E. and Kraxner, P. (1997) Investigations of Stable Molybdenum Carbene Complexes for the Metathesis Synthesis of Dialkylsubstituted Poly $(p$ phenylenevinylene)s (PPVs). Journal of Molecular Catalysis A, 115, 21-28. https://doi.org/10.1016/S1381-1169(96)00079-9

[23] Thorn-Csányi, E. and Kraxner, P. (1997) All-Trans Oligomers of 2,5-Dialkyl-1,4Phenylenevinylenes-Metathesis Preparation and Characterization. Macromolecular Chemistry and Physics, 198, 3827-3843. https://doi.org/10.1002/macp.1997.021981205

[24] Thorn-Csányi, E. and Kraxner, P. (1998) Synthesis of Soluble All-Trans Oligomers of 2,5-Diheptyloxy-p-Phenylenevinylene via Olefin Metathesis. Macromolecular Rapid Communications, 19, 223-228. https://doi.org/10.1002/marc.1998.030190413

[25] Schlick, H., Stelzer, F., Tasch, S. and Leising, G. (2000) Highly Luminescent Poly[( $m$-phenylenevinylene)-co-( $p$-phenylenevinylene)] Derivatives Synthesized via Metathesis Condensation (ADMET). Journal of Molecular Catalysis A, 160, 71-84. 
https://doi.org/10.1016/S1381-1169(00)00234-X

[26] Thorn-Csányi, E. and Herzog, O. (2004) Synthesis of Higher, Trans Configured Oligomers of Diisoalkyloxysubstituted Divinylbenzenes (PV-Oligomers) via Metathesis Telomerization of the Corresponding Lower Oligomers. Journal of Molecular Catalysis $A$, 213, 123-128. https://doi.org/10.1016/j.molcata.2003.12.002

[27] Joo, S.-H. and Jin, J.-I. (2004) All Hydrocarbon Main-Chain Thermotropic Liquid Crystalline Polymers, Poly(1,1'-biphenylene-4,4'-alkenediyl)s, Prepared by the ADMET Method and Their Hydrogenated Polymers, Poly(1,1'-Biphenylene-4,4'Alkanediyl)s. Journal of Polymer Science Part A: Polymer Chemistry, 42, 13351349. https://doi.org/10.1002/pola.11061

[28] Oakley, G.W. and Wagener, K. (2005) Solid-State Olefin Metathesis: ADMET of Rigid-Rod Polymers and Ring-Closing Metathesis. Macromolecular Chemistry and Physics, 206, 15-24. https://doi.org/10.1002/macp.200400137

[29] Pecher, J. and Mecking, S. (2007) Nanoparticles from Step-Growth Coordination Polymerization. Macromolecules, 40, 7733-7735. https://doi.org/10.1021/ma702048t

[30] Nomura, K., Morimoto, H., Imanishi, Y., Ramhani, Z. and Geerts, Y. (2001) Synthesis of High Molecular Weight trans-Poly(9,9-di-n-octylfluorene-2,7-vinylene) by the Acyclic Diene Metathesis Polymerization Using Molybdenum Catalysts. Journal of Polymer Science Part A: Polymer Chemistry, 39, 2463-2470. https://doi.org/10.1002/pola.1223

[31] Nomura, K., Miyamoto, Y., Morimoto, H. and Geerts, Y. (2005) Acyclic Diene Metathesis Polymerization of 2,5-Dialkyl-1,4-Divinylbenzene with Molybdenum or Ruthenium Catalysts: Factors Affecting the Precise Synthesis of Defect-Free, HighMolecular-Weight trans-Poly( $p$-phenylene vinylene)s. Journal of Polymer Science Part A: Polymer Chemistry, 43, 6166-6177. https://doi.org/10.1002/pola.21104

[32] Yamamoto, N., Ito, R., Geerts, Y. and Nomura, K. (2009) Synthesis of All-Trans High Molecular Weight Poly(n-alkylcarbazole-2,7-vinylene)s and Poly(9,9-dialkylfluorene-2,7-vinylene)s by Acyclic Diene Metathesis (ADMET) Polymerization Using Ruthenium-Carbene Complex Catalysts. Macromolecules, 42, 5104-5111. https://doi.org/10.1021/ma900775x

[33] Weychardt, H. and Plenio, H. (2008) Acyclic Diene Metathesis Polymerization of Divinylarenes and Divinylferrocenes with Grubbs-Type Olefin Metathesis Catalysts. Organometallics, 27, 1479-1485. https://doi.org/10.1021/om701277p

[34] Qin, Y. and Hillmyer, M.A. (2009) Poly(3-hexyl-2,5-thienylene Vinylene) by ADMET Polymerization of a Dipropenyl Monomer. Macromolecules, 42, 64296432. https://doi.org/10.1021/ma9009824

[35] Delgado, P.A., Liu, D.Y., Kean, Z. and Wagener, K.B. (2011) Synthesis of Poly(3Dodecyl-2,5-Thienylene Vinylene) by Solid-State Metathesis Polycondensation. Macromolecules, 44, 9529-9532. https://doi.org/10.1021/ma2020529

[36] Speros, J.C., Paulsen, B.D., White, S.P., Wu, Y., Jackson, E.A., Slowinski, B.S., Frisbie, C.D. and Hillmyer, M.A. (2012) An ADMET Route to Low-Band-Gap Poly(3hexadecylthienylene Vinylene): A Systematic Study of Molecular Weight on Photovoltaic Performance. Macromolecules, 45, 2190-2199.

https://doi.org/10.1021/ma3000434

[37] Speros, J.C., Paulsen, B.D., Slowinski, B.S., Frisbie, C.D. and Hillmyer, M.A. (2012) Band Gap And HOMO Level Control in Poly(thienylene vinylene)s Prepared by ADMET Polymerization. ACS Macro Letters, 1, 986-990. https://doi.org/10.1021/mz300326k

[38] Speros, J.C., Martinez, H., Paulsen, B.D., White, S.P., Bonifas, A.D., Goff, P.C., Fris- 
bie, C.D. and Hillmyer, M.A. (2013) Effects of Olefin Content and Alkyl Chain Placement on Optoelectronic and Morphological Properties in Poly(thienylene vinylenes). Macromolecules, 46, 5184-5194. https://doi.org/10.1021/ma4009115

[39] Zhang, Z. and Qin, Y. (2015) Synthesis and Characterization of Poly(selenylene vinylene) and Poly(selenylene vinylene)-co-poly(thienylene vinylene) through Acyclic Diene Metathesis (ADMET) Polymerization. ACS Macro Letters, 4, 679-683. https://doi.org/10.1021/acsmacrolett.5b00292

[40] Zhang, Z. and Qin, Y. (2016) Structurally Diverse Poly(thienylene vinylene)s (PTVs) with Systematically Tunable Properties through Acyclic Diene Metathesis (ADMET) and Postpolymerization Modification. Macromolecules, 49, 3318-3327. https://doi.org/10.1021/acs.macromol.6b00502

[41] Nomura, K., Yamamoto, N., Ito, R., Fujiki, M. and Geerts, Y. (2008) Exclusive End Functionalization of All-Trans Poly(fluorene vinylene)s Prepared by Acyclic Diene Metathesis Polymerization: Facile Efficient Synthesis of Amphiphilic Triblock Copolymers by Grafting Poly(ethylene glycol). Macromolecules, 41, 4245-4249. https://doi.org/10.1021/ma800558p

[42] Kuwabara, S., Yamamoto, N., Sharma, P.M.V., Takamizu, K., Fujiki, M., Geerts, Y. and Nomura, K. (2011) Precise Synthesis of Poly(fluorene-2,7-vinylene)s Containing Oligo(thiophene)s at the Chain Ends: Unique Emission Properties by the End Functionalization. Macromolecules, 44, 3705-3711. https://doi.org/10.1021/ma200638a

[43] Abdellatif, M.M. and Nomura, K. (2012) Precise Synthesis of Amphiphilic Multiblock Copolymers by Combination of Acyclic Diene Metathesis (ADMET) Polymerization with Atom Transfer Radical Polymerization (ATRP) and Click Chemistry. ACS Macro Letters, 1, 423-427. https://doi.org/10.1021/mz300061a

[44] Takamizu, K., Inagaki, A. and Nomura, K. (2013) Precise Synthesis of Poly(fluorene vinylene)s Capped with Chromophores: Efficient Fluorescent Polymers Modified by Conjugation Length and End-Groups. ACS Macro Letters, 2, 980-984. https://doi.org/10.1021/mz400455b

[45] Nomura, K., Haque, T., Onuma, T., Hajjaj, F., Asano, M.S. and Inagaki, A. (2013) Precise One-Pot Synthesis of End-Functionalized Conjugated Multi-Block Copolymers via Combined Olefin Metathesis and Wittig-Type Coupling.Macromolecules, 46, 9563-9574. https://doi.org/10.1021/ma4022554

[46] Nomura, K., Haque, T., Miwata, T., Inagaki, A. and Takamizu, K. (2015) Precise One-Pot Synthesis of Fully Conjugated End Functionalized Star Polymers Containing Poly(fluorene-2,7-vinylene) (PFV) Arms. Polymer Chemistry, 6, 380-388. https://doi.org/10.1039/C4PY01287A

[47] Nomura, K. and Abdellatif, M.M. (2010) Precise Synthesis of Polymers Containing Functional End Groups by Living Ring-Opening Metathesis Polymerization (ROMP): Efficient Tools for Synthesis of Block/Graft Copolymers. Polymer, 51, 1861-1881. https://doi.org/10.1016/j.polymer.2010.02.028

[48] Abdellatif, M.M. and Nomura, K. (2013) Precise Synthesis of End-Functionalized Oligo(2,5-dialkoxy-1,4-phenylene vinylene)s with Controlled Repeat Units via Combined Olefin Metathesis and Wittig-type Coupling. Organic Letters, 15, 16181621. https://doi.org/10.1021/ol400397p

[49] Abdellatif, M.M., Yorsaeng, S., Inagaki, A. and Nomura, K. (2014) Synthesis of End Functionalized Oligo(2,5-dialkoxy-1,4-phenylene vinylene)s. Macromolecular Chemistry and Physics, 215, 1973-1983. https://doi.org/10.1002/macp.201400163

[50] Hillmyer, M.A., Nguyen, S.B.T. and Grubbs, R.H. (1997) Utility of a Ruthenium Metathesis Catalyst for the Preparation of End-Functionalized Polybutadiene. Ma- 
cromolecules, 30, 718-721. https://doi.org/10.1021/ma961316n

[51] Pitet, L.M. and Hillmyer, M.A. (2011) Carboxy-Telechelic Polyolefins by ROMP Using Maleic Acid as a Chain Transfer Agent. Macromolecules, 44, 2378-2381. https://doi.org/10.1021/ma102975r

[52] Lin, T.-W., Chou, C.-M., Lin, N.-T., Lin, C.-L. and Luh, T.-Y. (2014) End Group Modification of Polynorbornenes. Macromolecular Chemistry and Physics, 215, 2357-2364. https://doi.org/10.1002/macp.201400284

[53] Miyashita, T. and Nomura, K. (2016) Catalytic One-Pot Synthesis of End-Functionalized Poly(9,9'-di- $n$-octylfluorenevinylene)s by Acyclic Diene Metathesis (ADMET) Polymerization Using Ruthenium-Carbene Catalysts. Macromolecules, 49, 518-526. https://doi.org/10.1021/acs.macromol.5b02287

[54] Miyashita, T., Inagaki, A. and Nomura, K. (2016) One-Pot Synthesis of End-Functionalized Conjugated Polymers by Combined Acyclic Diene Metathesis (ADMET) Polymerization with Wittig-Type Coupling. Journal of the Japan Petroleum Institute, 59, 197-203. https://doi.org/10.1627/jpi.59.197

\section{Scientific Research Publishing}

Submit or recommend next manuscript to SCIRP and we will provide best service for you:

Accepting pre-submission inquiries through Email, Facebook, LinkedIn, Twitter, etc. A wide selection of journals (inclusive of 9 subjects, more than 200 journals)

Providing 24-hour high-quality service

User-friendly online submission system

Fair and swift peer-review system

Efficient typesetting and proofreading procedure

Display of the result of downloads and visits, as well as the number of cited articles

Maximum dissemination of your research work

Submit your manuscript at: http://papersubmission.scirp.org/

Or contact gsc@scirp.org 